\title{
Investigation of angucycline compounds as potential drug candidates against SARS Cov- 2 main protease using docking and molecular dynamic approaches
}

\author{
Hazem Abbas Al-Bustany ${ }^{1}$ (D) $\cdot$ Selami $^{E} \operatorname{Sran}^{2}$ (D) $\cdot$ Ebru Ince $^{3}$ (D) $\cdot$ Necmettin Pirinccioglu $^{4}$ (ID)
}

Received: 27 December 2020 / Accepted: 25 March 2021 / Published online: 10 April 2021

(c) The Author(s), under exclusive licence to Springer Nature Switzerland AG 2021

\begin{abstract}
The emerged Coronavirus disease (COVID-19) causes severe or even fatal respiratory tract infection, and to date there is no FDA-approved therapeutics or effective treatment available to effectively combat this viral infection. This urgent situation is an attractive research area in the field of drug design and development. One of the most important targets of SARScoronavirus-2 (SARS Cov-2) is the main protease (3CLpro). Actinomycetes are important resources for drug discovery. The angucylines that are mainly produced by Streptomyces genus of actinomycetes exhibit a broad range of biological activities such as anticancer, antibacterial and antiviral. This study aims to investigate the binding affinity and molecular interactions of 157 available angucycline compounds with 3CLpro using docking and molecular dynamics simulations. MM-PBSA calculations showed that moromycin A has a better binding energy $\left(-30.42 \mathrm{kcal} \mathrm{mol}^{-1}\right)$ compared with other ligands (in a range of -18.66 to $\left.-22.89 \mathrm{kcal} \mathrm{mol}^{-1}\right)$ including saquayamycin $\mathrm{K} 4\left(-21.27 \mathrm{kcal} \mathrm{mol}^{-1}\right)$ except the co-crystallized ligand N3. However, in vitro and in vivo studies are essential to assess the effectiveness of angucycline compounds against coronavirus.
\end{abstract}

\section{Graphic abstract}

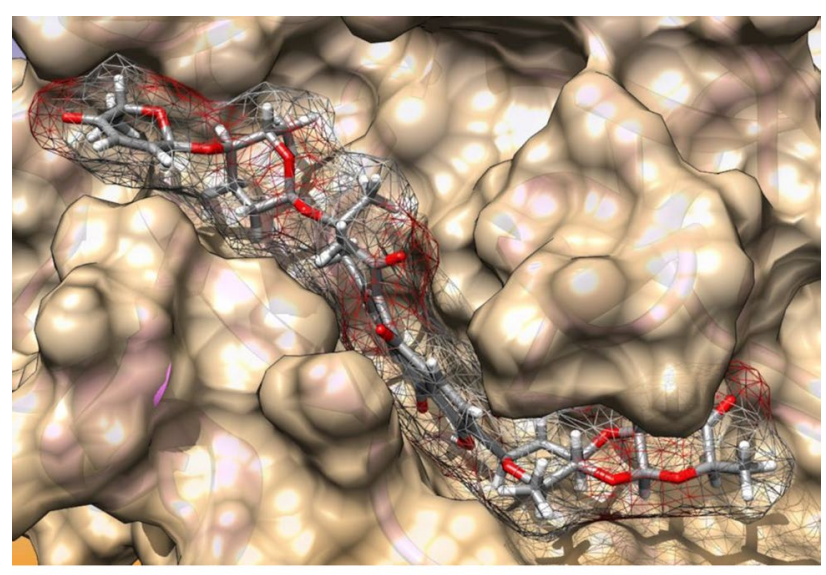

Molecular Dynamics Studies of Moromycin A-COVID-19 $\mathrm{M}^{\text {pro }}$ Complex

Keywords Angucycline compounds · COVID-19 $\cdot$ Main protease $\cdot$ 3CLpro $\cdot$ Inhibitors $\cdot$ Molecular modelling $\cdot$ Docking $\cdot$ Molecular dynamics simulation $\cdot$ MM-PBSA

Necmettin Pirinccioglu

pirincn@dicle.edu.tr

Extended author information available on the last page of the article 


\section{Introduction}

Wuhan Novel Coronavirus (2019-nCoV), which is known as Coronavirus disease 2019 (COVID-19) outbreak, has become worldwide pandemic and caused deaths of numerous infected people [1]. So there is an immediate and a large-scale research campaign to design and discover definitive therapeutic agents against this fatal virus. To date, there is no effective antiviral therapy [2], but few vaccines have recently been approved to combat the COVID-19 infection. Most of the immediate efforts focused on clinically approved known drug evaluation and virtual screening of available molecules from chemical libraries [3].

The main protease (3CLpro, also called $\mathrm{M}^{\mathrm{pro}}$ ), which is involved in processing the polyproteins that are translated from the viral RNA [4], is one of the most sought drug targets among coronaviruses [5]. There are no human proteases with similar cleavage specificity. Therefore, inhibitors for this protein are expected not to be competitive for the host.

There have been recent studies on developing inhibitors targeting 3CLpro based on structure-based ligand design and molecular modelling and even in vitro studies from available libraries [6-8]. This study aims to investigate the potentials of angucycline compounds as drug candidates against coronavirus. The angucyclines are the largest group of polyketides produced in streptomycetes via complex enzymatic biosynthetic pathways [9] and show a broad range of biological activities, such as antibacterial [10, 11], antitumor [12], antiviral [11, 13-15] and enzyme inhibitors [11]. The binding affinity of a total of 157 angucycline compounds against 3CLpro was screened by molecular docking. Molecular dynamics (MD) simulations were performed for the complexes of 3CLpro with saquayamycin $\mathrm{K} 4$ and moromycin $\mathrm{A}$, which produced the best docking scores and also for some other crystal 3CLpro complexes, namely N3 [7], 11r, 13a, 13b and 14b [6]. The binding energies for the complexes were calculated by MM-PBSA.

\section{Materials and methods}

\section{Docking}

The crystal structure (PDB ID: 6LU7) for 3CLpro is obtained from Protein DataBank (PDB) (http://www.rcsb. org) [6]. All the angucyclines were previously prepared and ready for docking study [16]. They were drawn by ChemDraw and converted to 3D structures and minimized by Discovery Studio Visualizer [17]. The ligands and the protein were prepared by MGL Tools program [18], and they were saved in PDBQT file format. The binding site of 3CLpro enzyme was selected for grid calculations by taking the advantage of the co-crystallized N3 ligand contained in the crystal structure of 6LU7.pdb file. A grid box with the dimensions of $18 \times 24 \times 20 \AA$ was placed to $-9.66,11.50$ and 68.81 points through $\mathrm{x}, \mathrm{y}$ and $\mathrm{z}$ coordinates, respectively. Each running gave a total of 9 docking poses for each ligand. Molecular docking was performed using AutoDock Vina 1.1.2 [19], running on Windows 8.1 operating system with 4 CPUs and 12 GB of RAM that generated 9 poses for each docked ligand.

\section{Drug-likeness}

The ADME properties of saquayamycin K4 and moromycin A were defined by using SwissADME Web site [20].

\section{MD simulations}

All MD simulations were conducted using the Assisted Model Building with Energy Refinement (AMBER, v.19.0) software package [19] running on TRUBA clusters (TUBITAK). AM1-Bcc (the Austin model with bond and charge correction) atomic partial charges for the ligands were calculated by the antechamber module of the AMBER (v.19.) package [21]. Xleap as implemented in AMBER was employed to prepare parameter/topology and coordinate files and to solvate and neutralize the system for the MD simulations. The complexes were solvated in an octagonal periodic box containing explicit TIP3P [22] with dimensions that its boundaries extend at least $10 \AA$ from any solute atom. This is a very popular solvation model for MD simulations because of its simplicity and computational efficiency. The ff19SB force field was used for the protein, while the General Amber Force Field (GAFF) [23] was employed for the ligands because it can handle small organic molecules. Three-dimensional and surface structures were displayed using the Chimera (UCSF) software package [24].

The complex including water and sodium ions was minimized in two steps. In the first step, the enzyme and the ligand were kept fixed; only the water molecules were allowed to move. In the second step, all of the atoms were allowed to move. In both steps, energy minimization was performed in 2000 steps: 1000 steps with the steepest descent method and 1000 steps with the conjugate gradient method. Heating was performed for 200 ps, where the protein-ligand complex was restrained with a force constant of $50 \mathrm{kcal} \mathrm{mol}^{-1} \AA^{-2}$. Equilibration was performed for $1 \mathrm{~ns}$ in the isothermal-isobaric (NPT) ensemble, restraining the protein-ligand complex by $1 \mathrm{kcal} \mathrm{mol}^{-1} \AA^{-2}$. Final simulations (the production phase) were performed for $50 \mathrm{~ns}$ in the 
NPT ensemble at a temperature of $300 \mathrm{~K}$ and a pressure of $1 \mathrm{~atm}$. The step size was $2 \mathrm{fs}$ during the entire simulation. A Langevin thermostat and barostat were used to couple the temperature and pressure. The SHAKE algorithm was applied to constrain all bonds containing hydrogen atoms [25]. The nonbonded cutoff was kept at $10 \AA$, and longrange electrostatic interactions were treated using the particle mesh Ewald (PME) [26] method with a fast Fourier transform grid with a spacing of approximately $0.1 \mathrm{~nm}$. Trajectory snapshots were taken 1-ps intervals, and these were later used in the analysis.

The root-mean-square deviation (RMSD) and rootmean-square fluctuation (RMSF) were analyzed by cpptraj as implemented in AMBER from MD simulations, and the results were plotted using MS Excel.

\section{MM-PB(GB)SA}

The Molecular Mechanics Poisson-Boltzmann Surface Area (MM-PBSA) or Molecular Mechanics Generalized Born Surface Area (MM-GBSA) module of AMBER (v.19.0) was applied to compute the binding free energy $\left(\Delta G_{\text {bind }}\right)$ of each complex $[27,28]$. The application of the method is detailed in our previous works [29, 30]. For each complex, 2500 frames were extracted from a total of 25,000 frames calculated over a period of $50 \mathrm{~ns}$.

\section{Results}

The 2D structures of the compounds saquayamycin K4, moromycin, N3, 11r, 13a, 13b and $\mathbf{1 4 b}$ are shown in Fig. 1. The structures of all the angucyclines are provided in Supplementary Information (Table S1). The active site of 3CLpro consists of a large pocket with deeper three wells (Fig. 2), involving a catalytic dyad composed of CYS145 and HIS41 and four subsites (S1, S2, S3 and S4) [31-35] The S1 subsite involves PHE140, LEU141, ASN142, HIS163, GLU166 and HIS172 residues. This subsite is further divided which includes THR25, THR26 and LEU27. The $\mathrm{S} 2$ subsite has a hydrophobic character, which is comprised of HIS41, MET49, TYR54, MET165 and ASP187. On the other hand, the S3 subsite is solvent-exposed, and therefore, it can accommodate a wider range of functional groups $[6,8]$. The S4 binding subsite is composed of MET165, LEU167, PHE185, GLN189 and GLN192 residues [6].

To validate the application of AutoDock Vina for the docking of the ligands into the protein, N3 ligand was extracted and re-docked into the active site of the enzyme and the generated docked poses were compared with the co-crystallized pose with a RMSD of $1.711 \AA$. Docking of N3 by Dock 6 [36] also produced a similar conformational pattern with the co-crystallized ligand with a RMSD of $1.390 \AA$ (Fig. 3).

All the compounds were well docked into this pocket using AutoDock Vina software (Figs. 4, 5, 6, 7, 8, 9, 10). Docking analyses indicated that 12 candidates have docking scores lower (the lower the score the better the binding affinity) than $-9.5 \mathrm{kcal} / \mathrm{mol}$ as summarized in Table 1 . They all have better docking scores compared to the current inhibitors, $\mathbf{N 3}$ [7], 11r, 13a, 13b and 14b [6]. The top four candidates to bind with 3CLpro among the angucycline compounds were saquayamycin K4, moromycin A, saquayamycin B and saquayamycin B-2. The docking scores of the rest of angucyclines are demonstrated in Supplementary Information (Table S2). They all bind to the protein via hydrogen bonds and hydrophobic interactions.

MD simulation was performed for the complexes of the best scoring ligands, namely saquayamycin $\mathrm{K} 4$, moromycin $\mathrm{A}$ and the other ligands (N3, 11r, 13a, 13b and 14a); each complex was simulated for a period of $50 \mathrm{~ns}$. The MD simulations of these two angucyclines are expected to reflect the mode of the action of the rest of angucyclines. The rootmean-square deviation (RMSD) and root-mean-square fluctuation (RMSF) obtained from MD trajectories for the complexes of 3CLpro with all the ligands are presented in Figs. 4 and 5 . The lowest energy structures for the complexes are demonstrated in Figs. 6, 7, 8, 9, 10, 11, 12 as we will see in the discussion section. The binding energies calculated from MD trajectories by MM-PBSA are summarized in Table 1.

\section{Discussion}

The COVID-19 has caused one of the deadliest outbreaks in the present time. Prevention of the newly emerging COVID19 infection is very challenging. The possibility of in silico methods can be utilized to find solutions with fewer trials and errors and thus saving both time and costs of the research. The docking study provides a time saving, shorter and cheaper approach for drug development.

RMSD and RMSF obtained from MD trajectories for the complexes of 3CLpro with all the ligands (Figs. 4 and 5) demonstrate that all the complexes have reached a conformationally stable structure and the residues involved in the interaction with the ligands, and ligands themselves are in compact status and they do not undergo significant dynamical changes during MD simulations except saquayamycin K4.

The comparison of the superimposed structures of the docked N3 by AutoDock Vina with the original X-ray coordinates indicates that the application of AutoDock for the docking of the ligands into the protein is reliable (Fig. 3). The N3 inhibitor has relatively a lower docking score $(-7.8 \mathrm{kcal} / \mathrm{mol})$ compared with almost of $2 / 3$ of 
Fig. 1 2D structures of the compounds saquayamycin $\mathrm{K} 4$, moromycin, N3, 11r, 13a, 13b and 14b

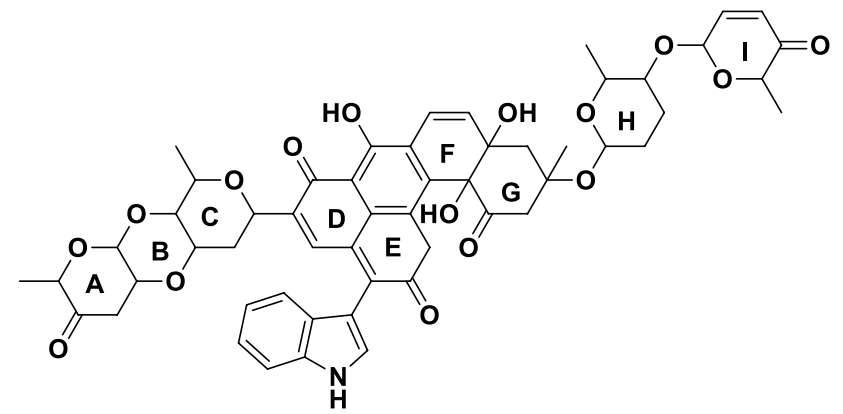

Saquayamycin K4<smiles>CC1OC(OC2CCC(OC3(C)CC(=O)c4c(ccc5c4C(=O)c4ccc(C6CC7OC8CC(=O)C(C)OC8OC7C(C)O6)c(O)c4C5=O)C3=O)C(C)O2)C=CC1=O</smiles>

Moromycin A<smiles>Cc1cc(C(=O)N[C@@H](C)C(=O)N[C@H](C(=O)N[C@@H](CC(C)N)C(=O)NC(/C=C/C(=O)OCc2ccccc2)C[C@@H]2CCNC2=O)C(C)C)no1</smiles><smiles>CC(C)(C)OC(=O)Nc1cccn([C@@H](CC2CCCCC2)C(=O)N[C@@H](CC2CCNC2=O)C(=O)C(=O)NC2CC2)c1=O</smiles>

11r<smiles>CC(C)(C)OC(=O)Nc1cccn([C@@H](CC2CC2)C(=O)N[C@@H](CC2CCNC2=O)C(=O)C(=O)NCc2ccccc2)c1=O</smiles>

$13 b$<smiles>NC1=CC=CC([C@H](CC2CC2)C(=O)NC(C[C@@H]2CCNC2=O)C(=O)C(=O)NCc2ccccc2)C1=O</smiles> 


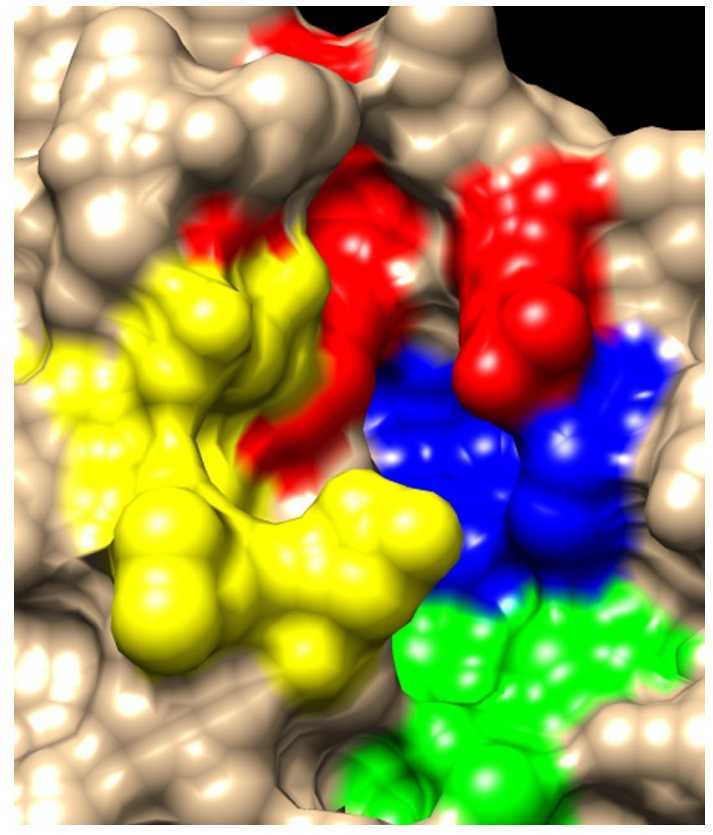

Fig. 2 Surface representation of the active site of 3CLpro highlighting its sub-pockets. Yellow and green represent the S1 subsite, blue represents the S2 subsite and red represents the S4 subsite

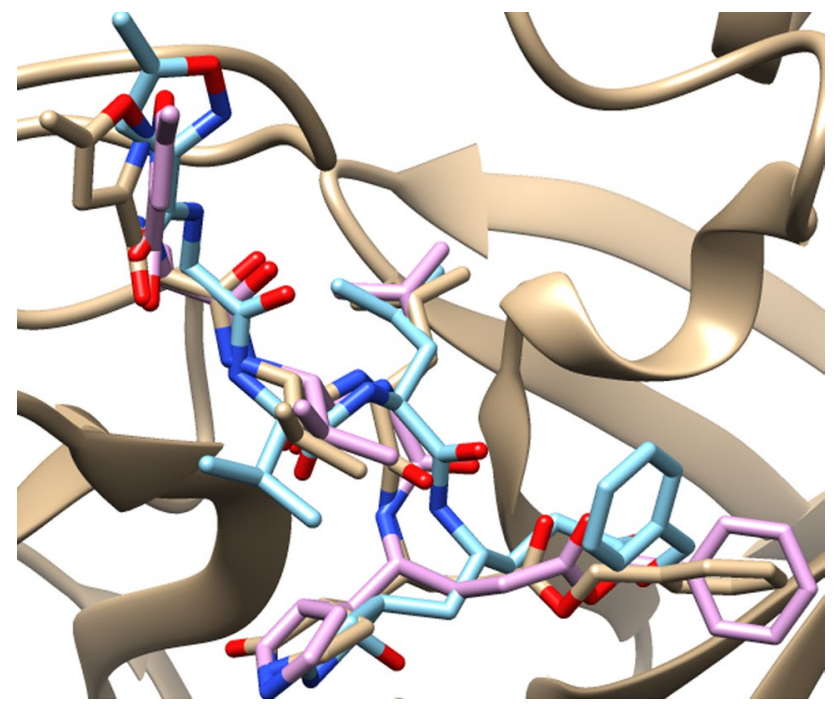

Fig. 3 The superimposed structures of original (light brown), docking by vina (light blue) and docking by Dock 6 (light magenta) with RMSD values of $1.711 \AA$ and $1.390 \AA$, respectively

the angucycline compounds (Table S1). The surface filling model shows that this ligand fully occupies the cavity in the active site (Fig. 6). It also involves hydrogen bonds and hydrophobic interactions to bind with 3CLpro (Fig. 6). After the MD calculation, the ligand has not undergone significant conformational changes within the active site compared to saquayamycin K4 and moromycin A. Although N3 is fitted well to the active site, it does not have so specific interactions compared to Moromycin A. The main noticeable interactions are that 1,2-isoxazole ring is held within a cavity composed of PRO168, THR190 and ALA191 residues via $\mathrm{CH}$-pi interactions, and the benzyl ring is sandwiched between HIS41 and MET49 via pi-pi and $\mathrm{CH}-$ pi interactions (Fig. 6). The CYS44 residue has also an interaction with the benzyl ring via pi-S interaction. The lactam ring interacts with SER144 and CYS145 via hydrogen bonds, and more markedly, GLN189 interacts with alanine and GLU166 with leucine next to alanine in $\mathbf{N} 3$ via hydrogen bonding (Fig. 6).

Docking results showed that saquayamycin $\mathrm{K} 4$ has the highest docking score against 3CLpro among angucycline compounds (Table 1) with a score of $-11.0 \mathrm{kcal} / \mathrm{mol}$. The ligand is well located in the active site, filling all the area in the pocket (Fig. 7). The binding mode of this compound involves hydrogen bonds and hydrophobic interactions. The complex of the compound with the protein includes hydrogen bonds with MET49, ASN142, GLY143, CYS145, HIS164, GLU166 and THR190 and hydrophobic interactions with LEU27, MET49 and CYS145. The binding also involves an NH-pi stacking with GLN189. HIS164, together with HIS41 and CYS145 residues, is located in the active site of the protein, and they are directly involved in the catalytic cleavage process. It is also reported that GLN189 is also involved in the catalytic process [8]. The indole ring of saquayamycin $\mathrm{K} 4$ has a crucial role in the binding, occupying one of three wells in the active site (Fig. 7), thus contributing to the binding energy and blocking the role of GLN189 in the catalytic process. On the other hand, the methyl group on the $\mathbf{H}$ ring of Saquayamycin K4 is also cradled in one of the other wells and interacts with LEU27 via hydrophobic interactions. After MD simulations, the ligand underwent a significant conformational change within the active site (Fig. 7). The binding energy obtained from MD simulations demonstrates that this compound has a comparable binding energy to the rest of the ligands except $\mathbf{N 3}$ (Table 1). The lowest energy structure for the complex of saquayamycin K4 with 3CLpro from MD calculations indicates that the $\mathbf{H}$ and $\mathbf{I}$ rings of the ligand lay out of the active pocket; however, the rest covers the major surface area of the active site, in a manner of "stone cave door" (Fig. 7). In this way, the residues involved in the catalysis are totally expected to be blocked from being accessed by the native substrate. The $\mathbf{A}, \mathbf{B}, \mathbf{C}$ and indole rings are held in one of the active site pockets, mainly made of hydrophobic residues. These two parts interact with LEU167, ALA191, PRO168 and the hydrophobic portion $\left(-\mathrm{CH}_{2} \mathrm{CH}_{2}-\right)$ of GLU166 and GLN189 on their side chains where GLN189 is thought to hold a meaningful role in the catalytic activity of the protein [8]. This residue as well as SER46 and GLU47 is involved in a hydrogen bond network with the ligand. GLU47 has twopoint interactions with the hydrogen donors attached to two 
Fig. 4 RMSD for the complexes of 3CLpro with all the ligands for $50 \mathrm{~ns}$ trajectory
Fig. 5 RMSF for the complexes of 3CLpro with all the ligands for $50 \mathrm{~ns}$ trajectory
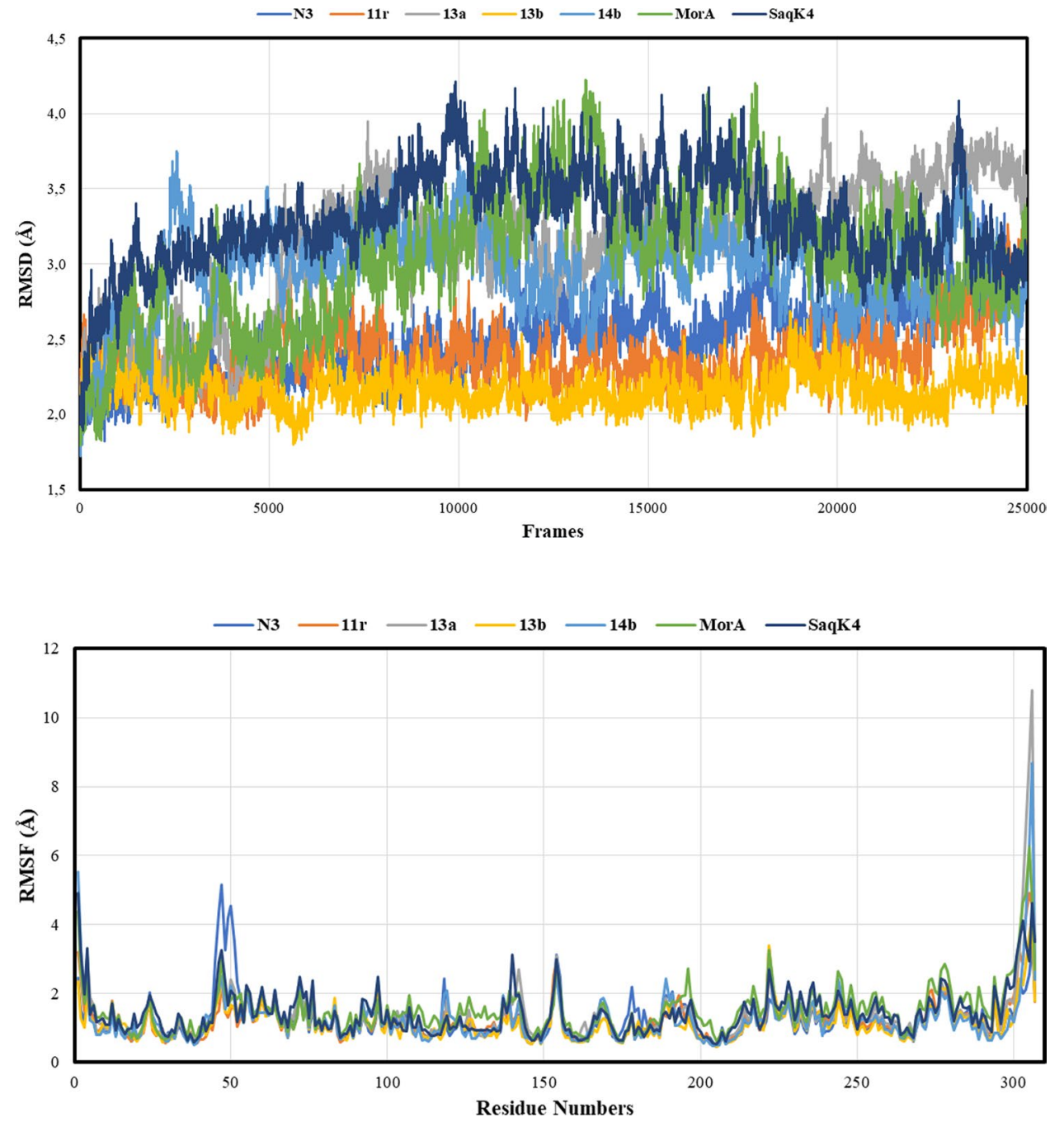

hydroxyls linked to the bridged carbons between the $\mathbf{F}$ and $\mathbf{G}$ rings, marked as $\mathbf{H 1 2}$ and H13 (Fig. 1), while SER46 has similarly two-point contacts with the phenolic oxygen $(\mathbf{O 2 0})$ and the carbonyl (O21) on the D ring. On the other hand, the amide hydrogens of GLN189 interact with the oxygen acceptors marked as $\mathbf{0 2 3 ,} \mathbf{0 2 6}$ and $\mathbf{0 3 8}$. So the hydroxyl group bearing H13 and $\mathbf{0 2 6}$ is chelated between GLU47 and GLN189. It is possible that this combination of the hydrogen bond network involving SER46, GLU47 and GLN189 contributes to a stronger binding of this ligand to the protein.

Moromycin A has a docking score of $-10.8 \mathrm{kcal} / \mathrm{mol}$ ranking the second with a similar binding mode of saquayamycin K4 (Fig. 8). It forms hydrogen bonds with the residues GLY143, CYS145, GLN189, and THR190, hydrophobic interactions with the residues LEU27, CYS145, PRO168 and ALA191 and alkyl-pi interactions with the residues HIS41, HIS163, MET165 and PRO168. In this complex, moromycin A also interacts with the main residues involved in the catalytic process. The binding energy obtained from MD simulations demonstrates that this angucycline has relatively comparable binding energy compared to the cocrystallized N3 ligand (Table 1) but higher binding energies compared to the other ligands (11r, 13a, 13b and 14b11r, 13a, 13b and 14b). The lowest energy conformer obtained from MD simulations for the complex of Moromycin A with 3CLpro indicates that the ligand resides in the active pocket composed of all the four sub-pockets (Fig. 8). The $\mathbf{C}, \mathbf{E}$ and $\mathbf{F}$ rings of the ligand are settled within the hydrophobic pocket of the active site. C ring interacts with ALA191 and ALA193 residues via van der Waals interactions, whereas E and F rings interact with LEU167, PRO168, MET49 and MET165 via $\mathrm{CH}-$ pi interactions. The $\mathrm{G}$ ring also interacts with MET49 and MET165 via van der Waals interactions. The carbonyl groups on the $\mathbf{E}$ and $\mathbf{G}$ ring form hydrogen bonds with GLN189 and 192 (Fig. 5). On the other hand, the methyl and $\mathrm{CH}_{2}$ groups in the $\mathbf{H}$ ring have $\mathrm{CH}$-pi interactions with the crucial residue HIS41, and the I ring is held within a pocket consisted of THR25, THR26, LEU27, VAL42 and CYS145 via both hydrophobic and hydrogen bonding (Fig. 8). 


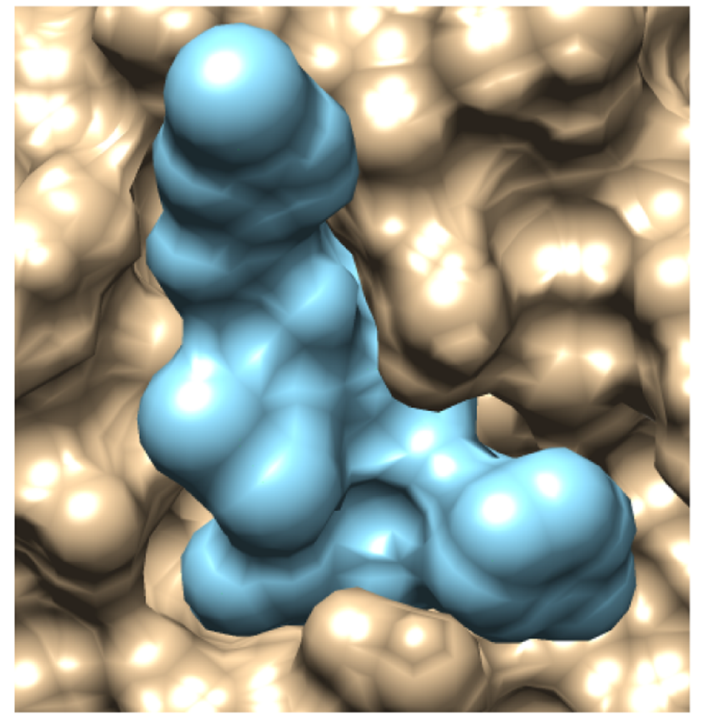

A

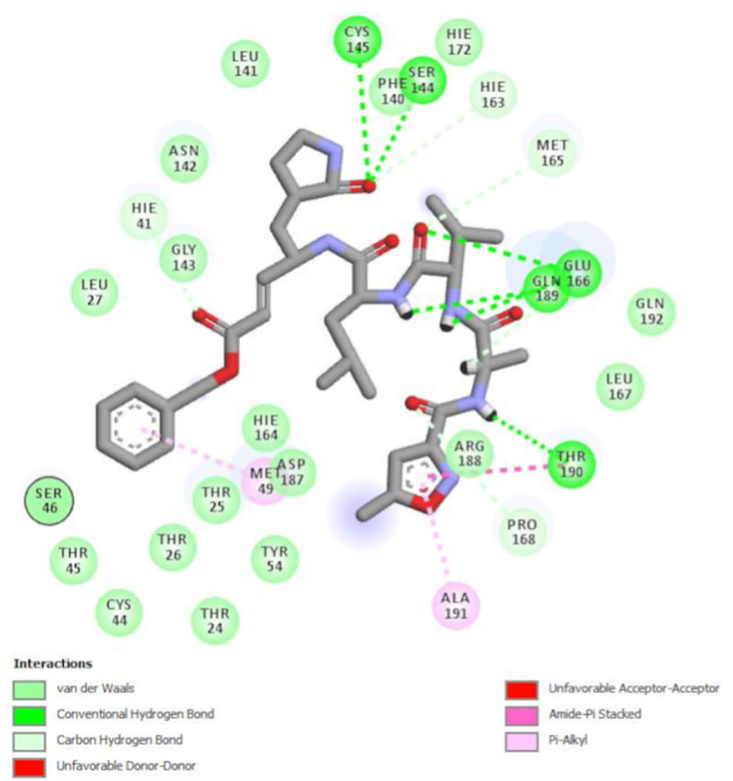

B

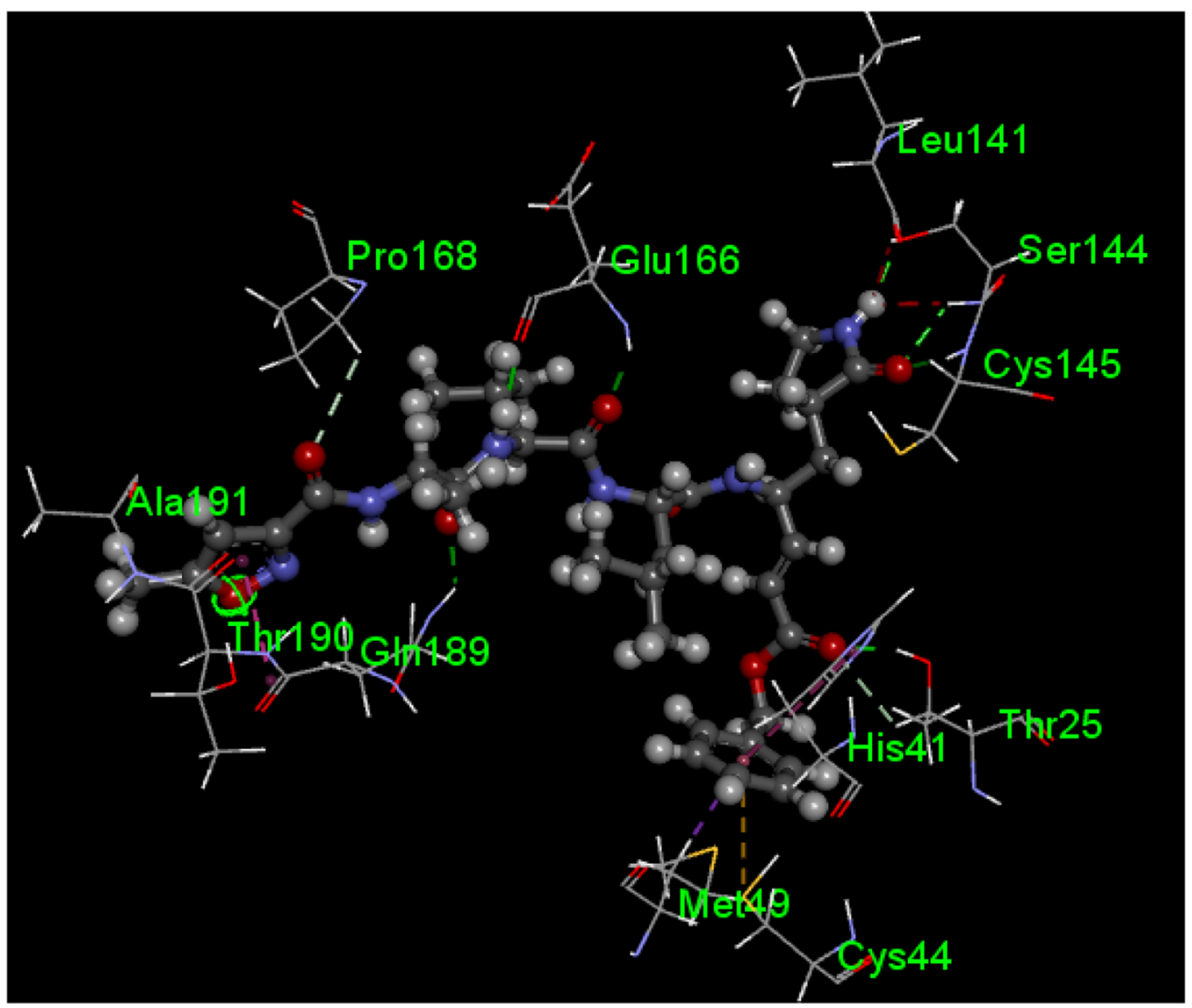

C

Fig. 6 (a) N3 docked to 3CLpro, (b) 2D structure of N3 docked to 3CLpro and (c) the binding mode of the complex of N3 with 3CLpro in the lowest energy structure obtained from MD simulations 


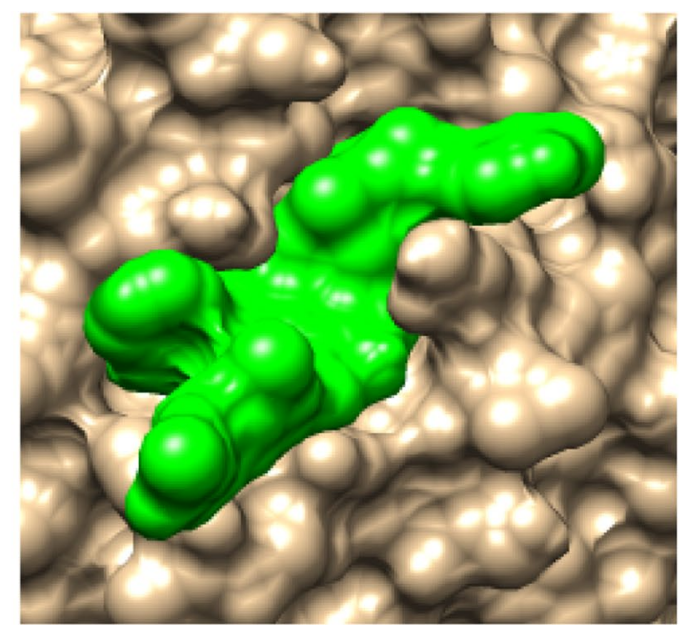

A
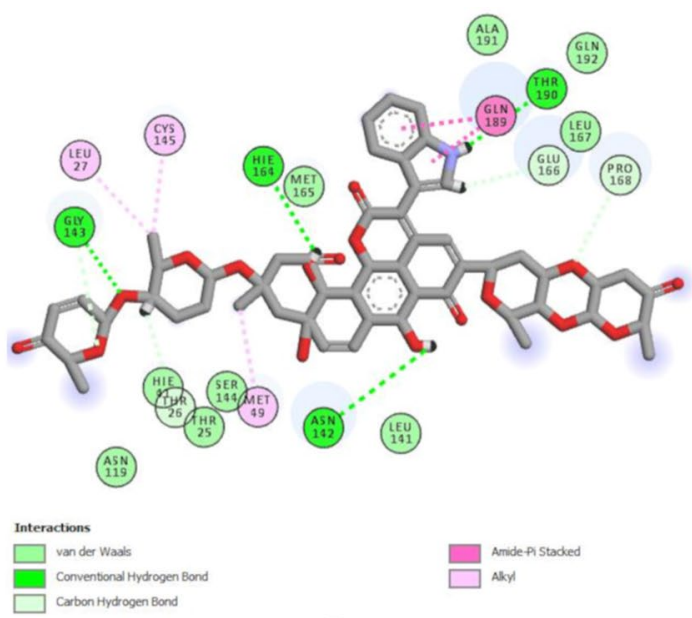

Carbon Hydrogen Bord

B

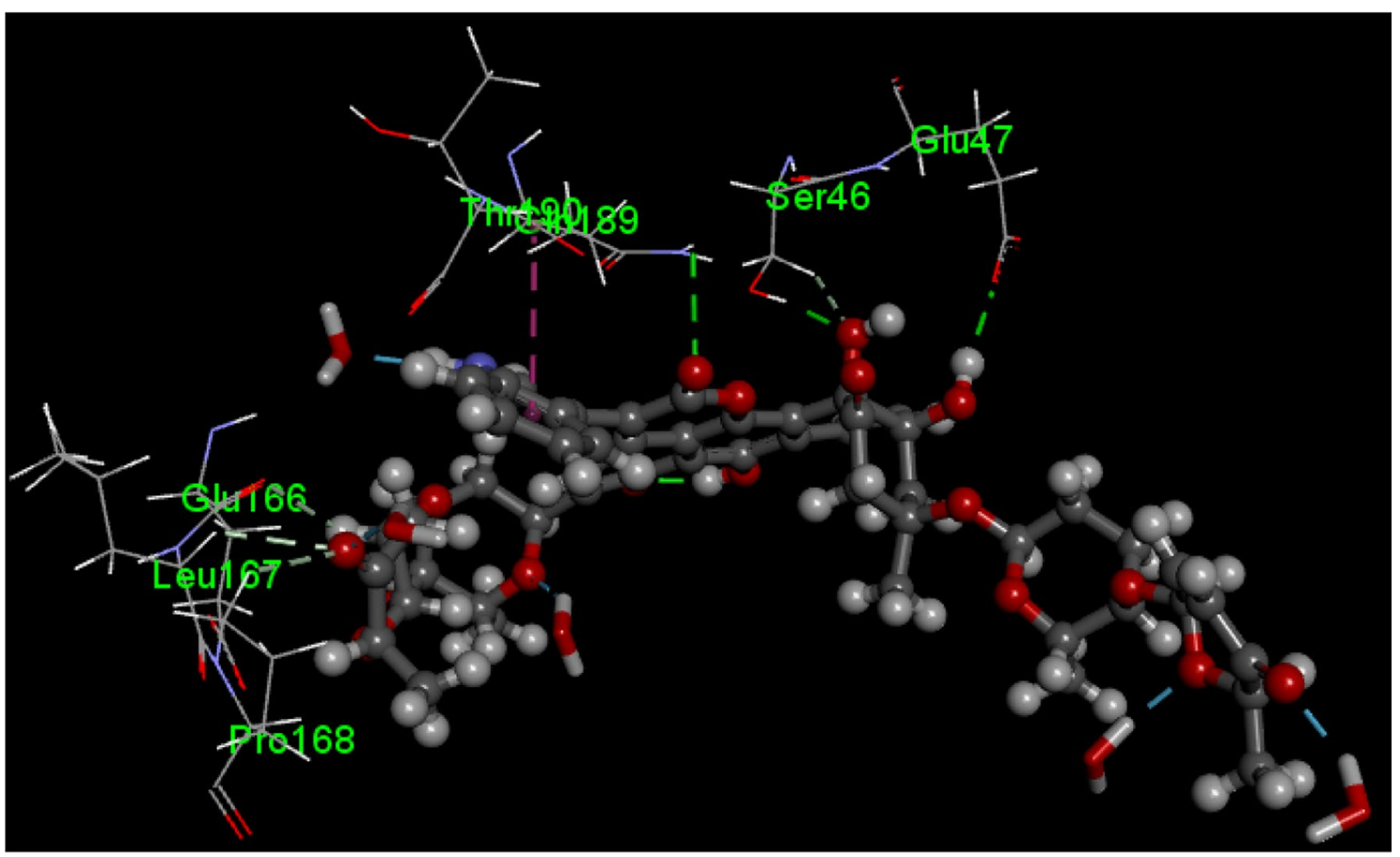

C

Fig. 7 (a) Saquayamycin K4 docked to 3CLpro, (b) 2D structure of saquayamycin K4 docked to 3CLpro and (c) the binding mode of the complex of saquayamycin K4 with 3CLpro in the lowest energy structure obtained from MD simulations

In a similar pattern to $\mathbf{N 3}$ inhibitor, 11r, 13a, 13b and 14b filled the active pocket in 3CLpro (Figs. 9, 10, 11, 12) with quite close docking scores. Following the MD simulations, all the ligands kept their conformation in the active sites with only slight changes compared to saquayamycin K4 (Figs. 9, 10, 11, 12). 11r has hydrogen bonds with CYS145 and HIS163 via the lactam ring and 3-phenylpropanoyl residue with GLN189. The cyclohexyl ring is located in one of the cavities in the pocket and N-benzyl group interacts with MET49 and CYS44 via $\mathrm{CH}_{2}-$ pi and S-pi interactions, respectively. Yet it is interesting to see that one molecule of water has penetrated into the cavity residing between HIS41, CYS145, and the carbonyl group of the lactam ring (Fig. 9). The cyclohexyl group and the lactam ring in 13a are located in the active site in a similar manner to $11 \mathbf{r}$ where the tert-butoxy carbonyl residue is located within a hydrophobic pocket consisted of MET49, THR24, THR25 and THR45. Interestingly, one water molecule has penetrated in the same cavity as in 11r, resided between HIS41 and ASP187 where the cyclohexyl ring is sandwiched between MET49 and 165 (Fig. 10) via hydrophobic interactions. This ring has also a contact with HIS41 via $\mathrm{CH}-$ pi interactions. 


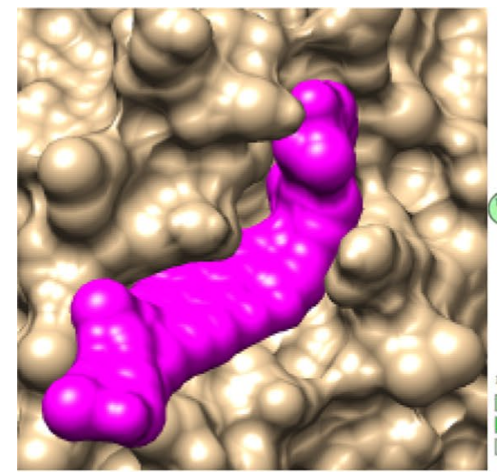

A

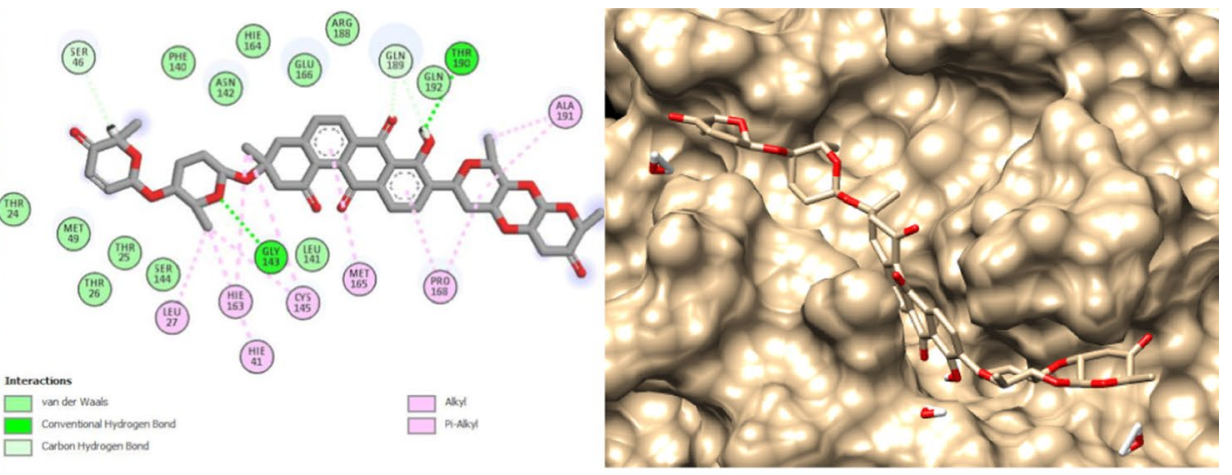

B

C

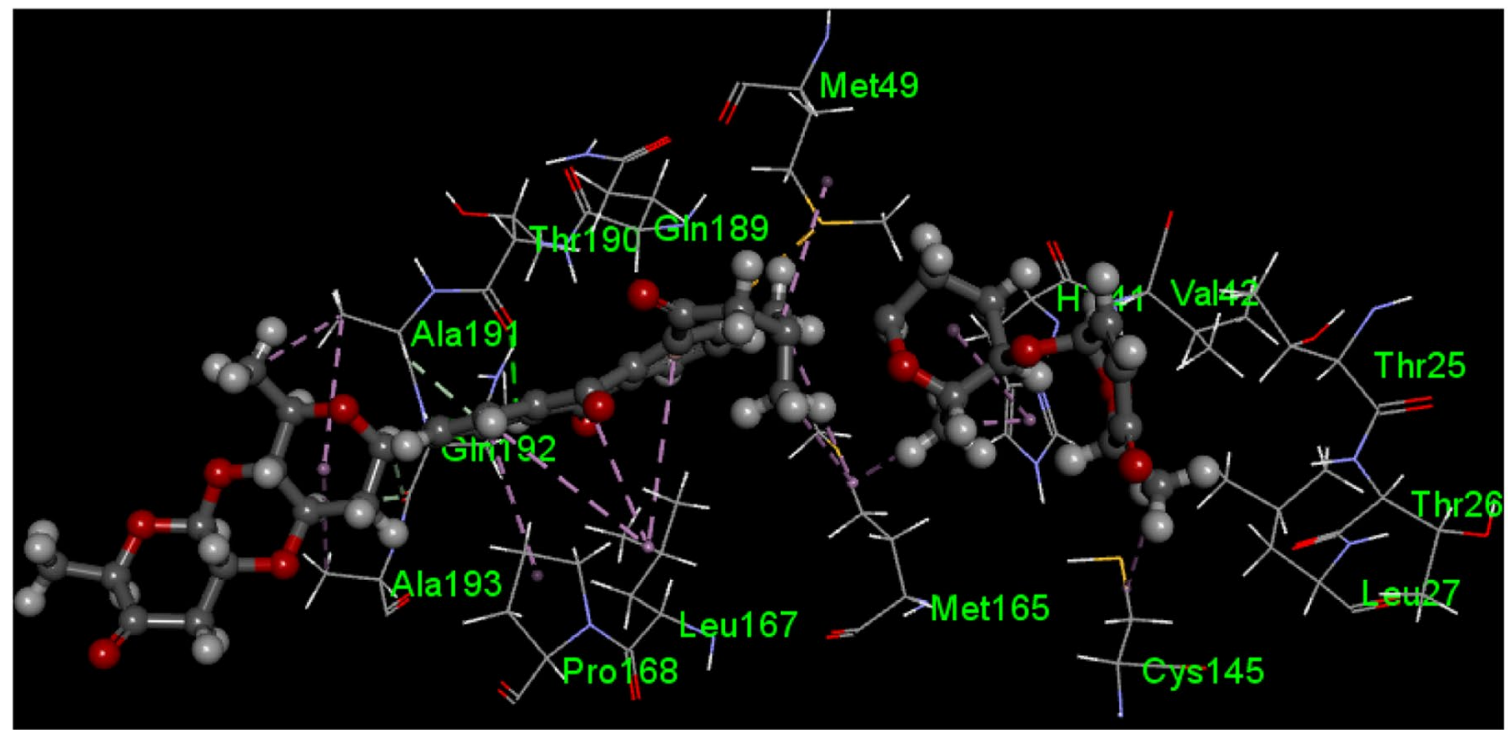

D

Fig. 8 (a) Moromycin A docked to 3CLpro, (b) 2D structure of moromycin A docked to 3CLpro, (c) the surface structure of the complex obtained from the MD simulations for $50 \mathrm{~ns}$ and (d) the bind-

Moreover, the cyclopropyl ring interacts with PRO168 and ALA191 via hydrophobic interactions. Lastly, the critical residue GLN189 has a hydrogen bond with $\mathrm{NH}$ attached to the cyclopropyl. In the complex of $\mathbf{1 3 b}$, the location of the lactam ring is switched with $\mathrm{N}$-benzyl group compared to those in 11r and 13a and the cyclopropyl ring is buried in the location where the cyclohexyl as in 11r and 13a (Fig. 11). The significant interactions are the hydrogen bonds of lactam ring with ASN119 and CYS145 residues. The tert-butyl group interacts with PRO168 via hydrophobic interactions and benzyl group interacts with ASN142 via NH-pi interactions. Furthermore, the cyclopropyl ring is sandwiched between HIS41 and MET165 via CH-pi and hydrophobic interactions, respectively. In this case, two molecules of waters were found in the active site one interacts with the carbonyl group on 3-amino-1H-prydine-2-one ring, and the other interacts with the carbonyl group close to the cyclopropyl ring. The lowest energy structure of $\mathbf{1 3 b}$ obtained from ing mode of the complex of Moromycin A with 3Clprot in the lowest energy structure obtained from MD simulations

MD simulations indicates that the orientation of the groups in the active sites resembles that of $\mathbf{1 4 b}$ where 3-amino1H-prydine-2-one interacts with GLU166 and HIS41 interacts with 3-cyclopropanoyl carbonyl (Fig. 11). Finally, as to the evaluation of the complex of $\mathbf{1 4 b}$ with 3CLpro, it is evident that $\mathbf{1 4 b}$ has a similar binding mode to that of $\mathbf{1 3 b}$ with regard to the orientation of the groups in the active site (Fig. 12). The lactam ring has hydrophobic interactions with THR25, LEU27 and VAL42, while HIS41 has hydrogen bonds with 3-cyclopropylpropanoyl carbonyl, and GLU166 and GLN189 have hydrogen bonds with the amino and carbonyl groups in 3-amino-1H-prydine-2-one ring, respectively. On the other hand, the interactions of cyclopropyl ring with MET165 via hydrophobic interactions, 3-amino1H-prydine-2-one ring with MET49 via $\mathrm{CH}$-pi interactions and the benzyl group with ASN142 via NH-pi interactions also contribute to the binding of this ligand to the protein. 
Fig. 9 (a) 11r docked to 3CLpro, (b) 2D structure of 11r docked to 3CLpro and (c) the binding mode of the complex of 11r with 3CLpro in the lowest energy structure obtained from MD simulations

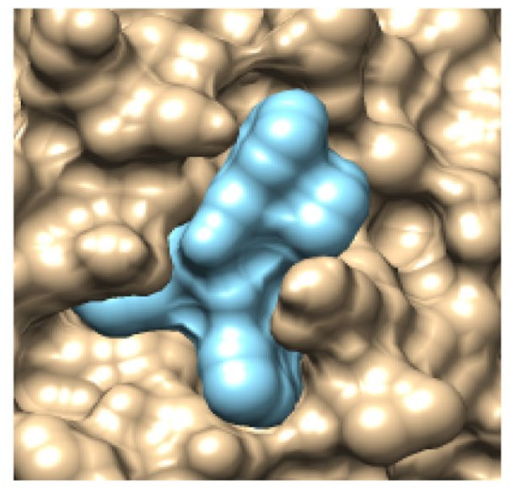

A
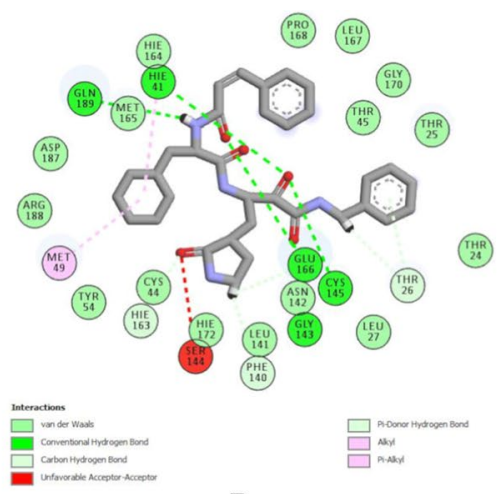

B

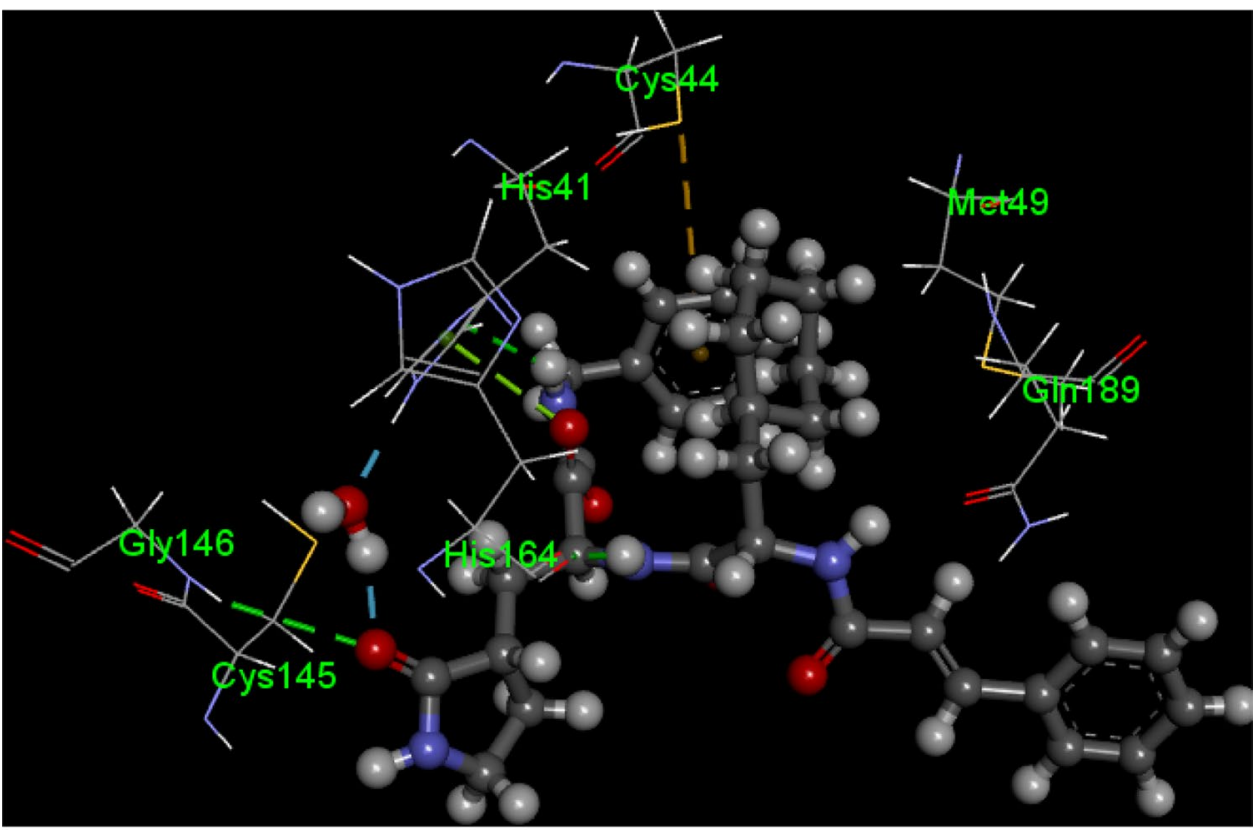

C

The above findings indicate that moromycin $\mathrm{A}$ and saquayamycin K4 showed high affinity and good binding interactions. These compounds have potential inhibitory effects for the catalytic dyad Cys145 and His41 as well as the other amino acids involved in the binding pocket. So their ability for the interaction with 3CLpro suggests further gains in the inhibition of the virus activity. Moreover, the interaction patterns of these compounds possess advantages compared to the known FDA drugs. This may make them potential for the treatment of COVID-19.

The drug-likeness properties of moromycin A and saquayamycin K4 were calculated by SwissADME. The results showed that both ligands have two violations according to Lipinski's rule of five due to their masses and containing more than 10 hydrogen bond acceptors. While both ligands seem to demonstrate P-glycoprotein substrate properties, saquayamycin $\mathrm{K} 4$ seems also to inhibit Cytochrome P450 2C9 enzyme. 
Fig. 10 (a) 13a docked to

3CLpro, (b) 2D structure of 13a docked to 3CLpro and (c) the

binding mode of the complex of

13a with 3 Clpro in the lowest

energy structure obtained from MD simulations

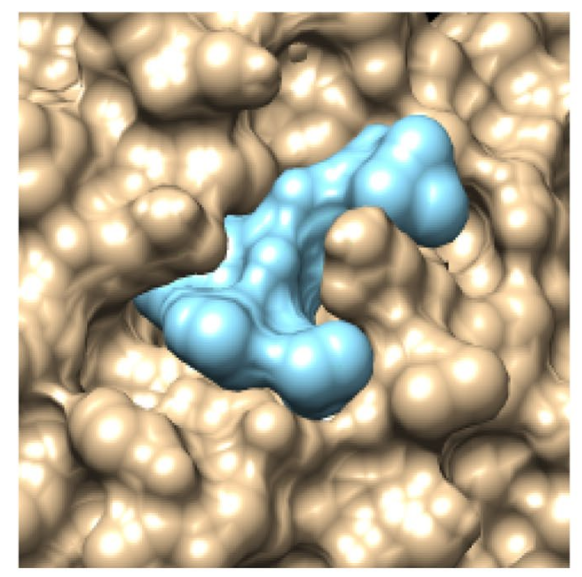

A

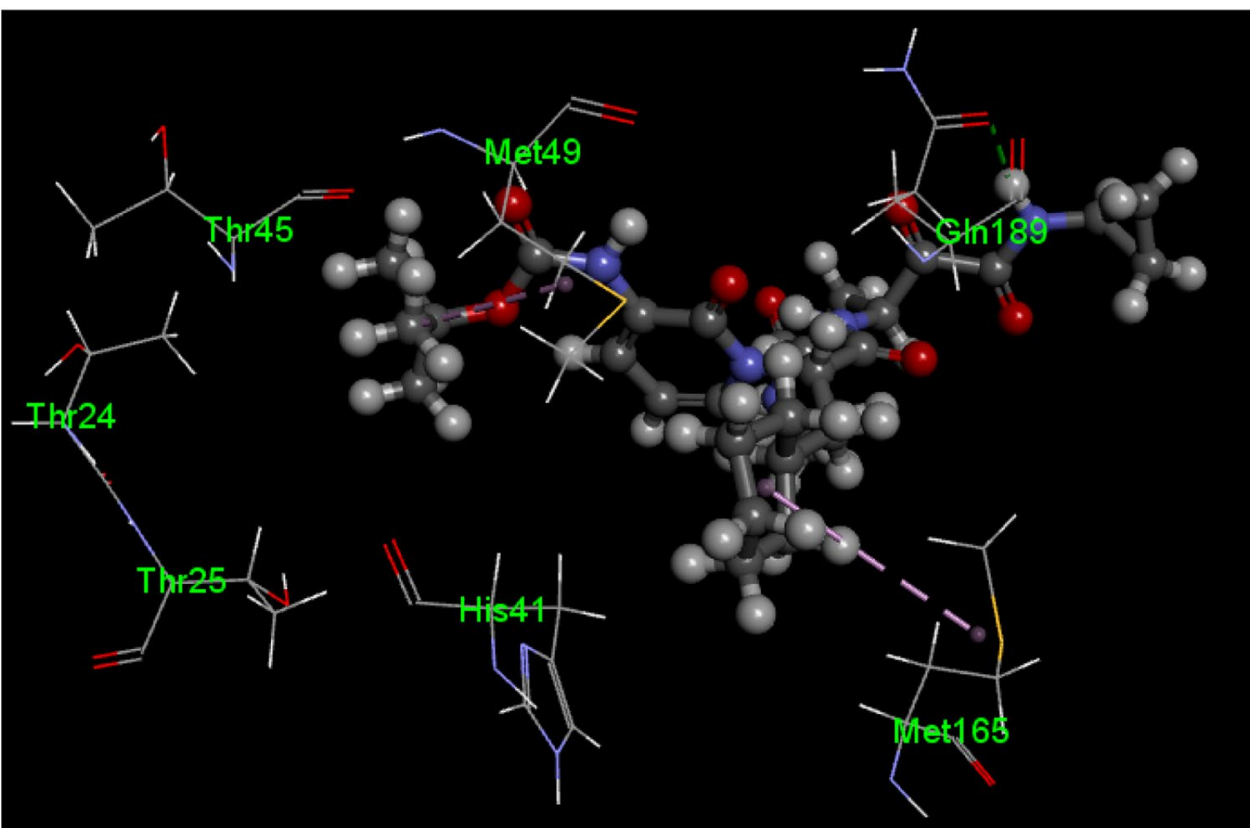

C (3i:
(1958)
(180)

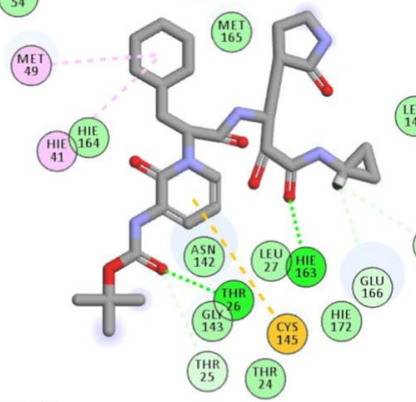

$\square^{\text {Interactions }}$

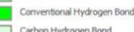

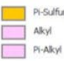

B

\section{(10)}


Table 1 Docking scores and binding energies (in $\mathrm{kcal} \mathrm{mol}^{-1}$ ) calculated by MM-PBSA for ligands to bind to 3CLpro

\begin{tabular}{lllll}
\hline Ligands & DS & MMGBSA & MMPBSA & NMODE \\
\hline Available inhibitors & & & & \\
N3 & -7.80 & $-45.712 \pm 5.30$ & $-31.38 \pm 5.17$ & $-34.35 \pm 6.81$ \\
& X-ray & $-51.46 \pm 9.74$ & $-35.11 \pm 8.14$ & $-33.76 \pm 5.39$ \\
$\mathbf{1 1 r}$ & -7.7 & $-41.91 \pm 4.29$ & $-24.08 \pm 4.82$ & $-27.40 \pm 7.11$ \\
$\mathbf{1 3 a}$ & -7.7 & $-33.83 \pm 7.17$ & $-22.72 \pm 5.32$ & $-26.10 \pm 8.35$ \\
$\mathbf{1 3 b}$ & -8.2 & $-30.50 \pm 4.13$ & $-20.993 \pm 4.15$ & $-26.02 \pm 6.27$ \\
14b & -7.9 & $-22.35 \pm 4.81$ & $-17.23 \pm 4.16$ & $-25.20 \pm 5.05$ \\
Angucycline compounds & & & & \\
Saquayamycin K4 & -11.0 & $-24.48 \pm 6.00$ & $-21.27 \pm 5.39$ & $-23.44 \pm 4.96$ \\
Moromycin A & -10.8 & $-49.26 \pm 5.83$ & $-30.42 \pm 5.12$ & $-30.49 \pm 6.71$ \\
Saquayamycin B & -10.4 & & & \\
Saquayamycin B-2 & -10.0 & & & \\
Kerriamycin B & -9.9 & & & \\
Kerriamycin A & -9.8 & & & \\
Urdamycin B & -9.8 & & & \\
Urdamycin_F & -9.7 & & & \\
BA 12100Z3 & -9.7 & & & \\
Saquayamycin A & -9.7 & & & \\
Saprolmycin C & -9.6 & & & \\
Saquayamycin K2 & -9.6 & & & \\
\hline
\end{tabular}

\section{Conclusion}

The protein-ligand complex interactions play a significant role in structure-based drug design. Docking analyses showed that the angucycline compounds are interacted with 3CLpro active site by hydrogen bonds and hydrophobic interactions, almost $2 / 3$ of them with relatively higher scores compared to some reported inhibitors. MD simulations and MM-PBSA results for the complex of saquayamycin $\mathrm{K} 4$, moromycin A and inhibitors indicated that moromycin A has a similar binding energy compared to that of the co-crystallized $\mathbf{N} \mathbf{3}$ inhibitor. Therefore, this compound and the others with the similar structural properties are considered promising lead candidates against COVID-19. The structure of moromycin A may be also used as a template for the design of new drug candidates against 3CLpro. However, in vitro and in vivo works are required to achieve a final conclusion about their efficiency as anti-coronavirus candidates. 
Fig. 11 (a) 13b docked to

3CLpro, (b) 2D structure of $\mathbf{1 3 b}$ docked to 3CLpro and (c) the

binding mode of the complex of

13b with 3Clpro in the lowest energy structure obtained from MD simulations

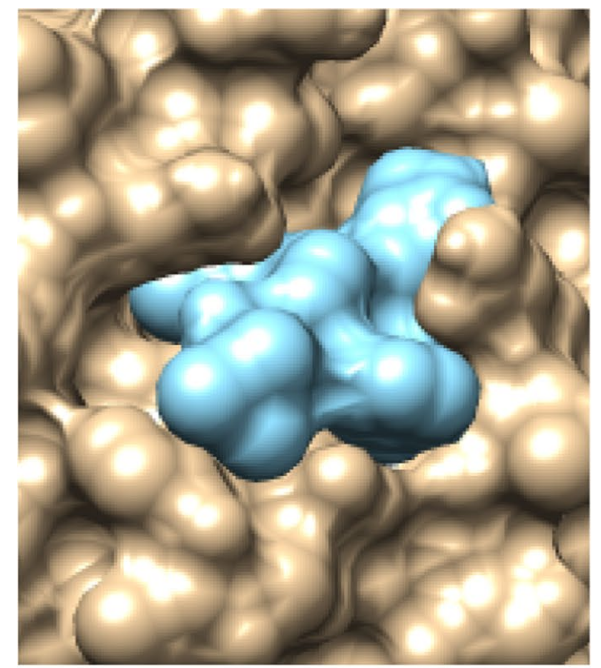

A
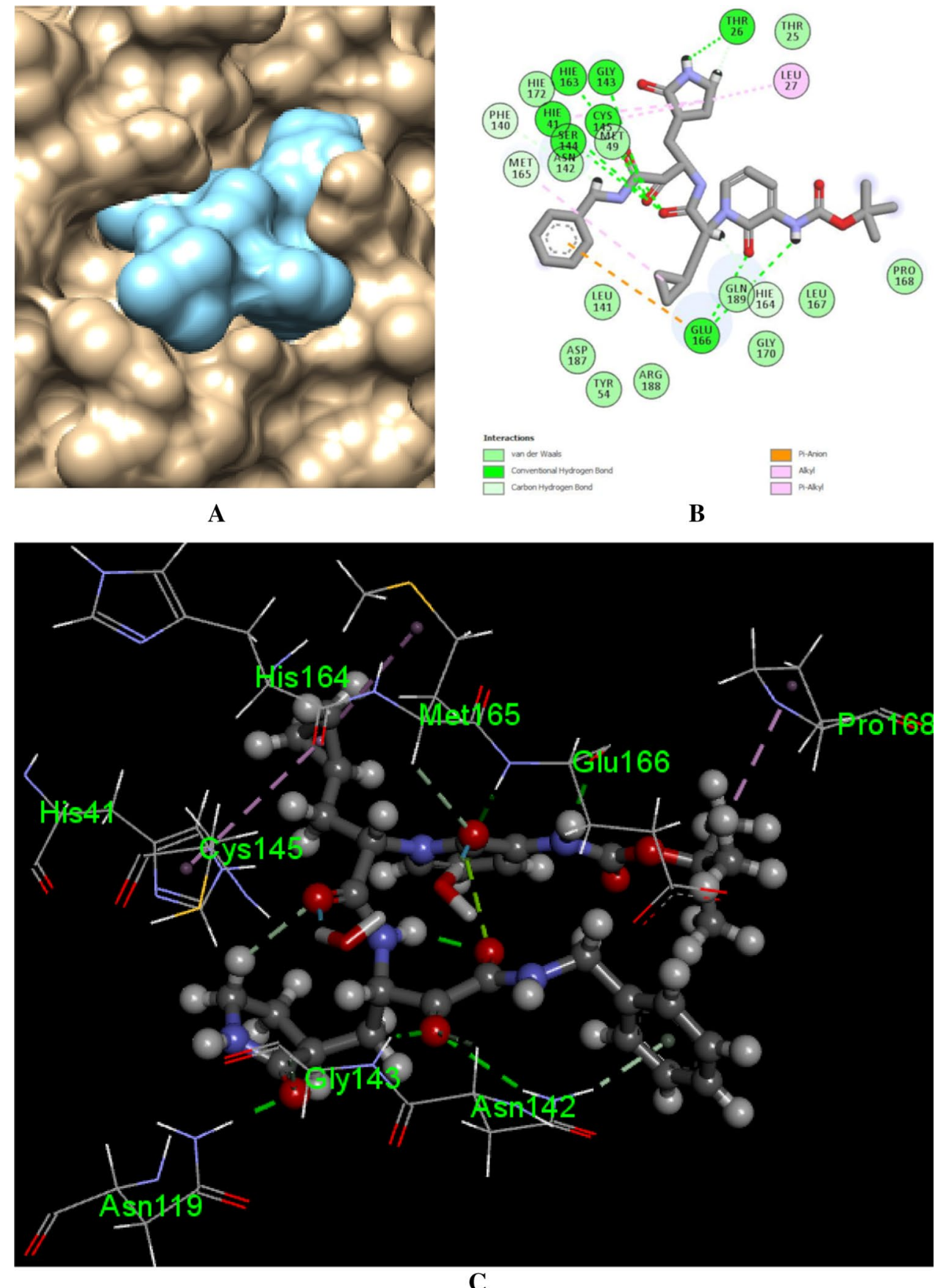
Fig. 12 (a) 14b docked to 3CLpro (left), (b) 2D structure of $\mathbf{1 4 b}$ docked to 3CLpro and (c) the binding mode of the complex of 14b with 3CLpro in the lowest energy structure obtained from MD simulations
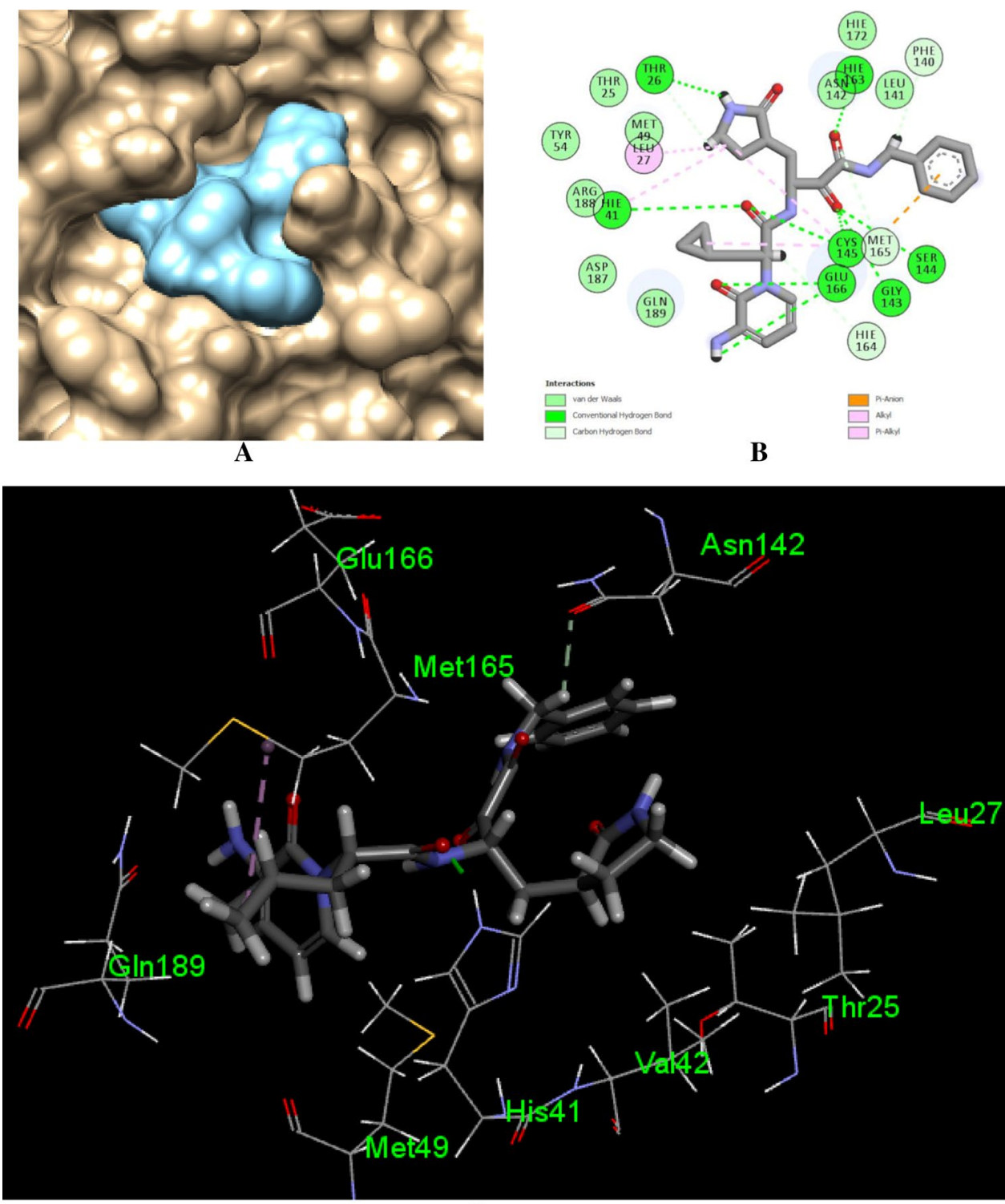

C
Supplementary Information The online version contains supplementary material available at https://doi.org/10.1007/s11030-021-10219-1.

Acknowledgements The authors thank The Scientific and Technological Research Council of Turkey (TUBITAK) for providing TRGRID facilities and DA Case (University of California, San Francisco) for a waiver license for AMBER (v.19.0).

\section{Declarations}

Conflict of interest The authors declare that they have no conflict of interest.

\section{References}

1. Sarkar B, Ullah MA, Johora FT, Taniya MA, Araf Y (2020) The Essential Facts of Wuhan Novel Coronavirus Outbreak in China and Epitope-based Vaccine Designing against COVID-19. bioRxiv:2020.2002.2005.935072. https://doi.org/10.1101/2020. 02.05 .935072

2. Ton A-T, Gentile F, Hsing M, Ban F, Cherkasov A (2020) Rapid identification of potential inhibitors of SARS-CoV-2 main protease by deep docking of 1.3 billion compounds. Mol Inf 39(8):e2000028. https://doi.org/10.1002/minf.202000028

3. Zhavoronkov A, Aladinskiy V, Zhebrak A, Zagribelnyy B, Terentiev V, Bezrukov D, Polykovskiy D, Shayakhmetov R, Filimonov A, Orekhov P, Yan Y, Popova O, Vanhaelen Q, Aliper A, Ivanenkov Y (2020) Potential COVID-2019 3C-like protease inhibitors designed using generative deep learning approaches. ChemRxiv. https://doi.org/10.26434/chemrxiv.11829102.v2 
4. Hilgenfeld R (2014) From SARS to MERS: crystallographic studies on coronaviral proteases enable antiviral drug design. FEBS J 281(18):4085-4096. https://doi.org/10.1111/febs.12936

5. Anand K, Ziebuhr J, Wadhwani P, Mesters JR, Hilgenfeld $\mathrm{R}$ (2003) Coronavirus main proteinase (3CLpro) structure: basis for design of anti-SARS drugs. Science (New York, NY) 300(5626):1763-1767. https://doi.org/10.1126/science.1085658

6. Jin Z, Du X, Xu Y, Deng Y, Liu M, Zhao Y, Zhang B, Li X, Zhang L, Peng C, Duan Y, Yu J, Wang L, Yang K, Liu F, Jiang R, Yang X, You T, Liu X, Yang X, Bai F, Liu H, Liu X, Guddat LW, Xu W, Xiao G, Qin C, Shi Z, Jiang H, Rao Z, Yang H (2020) Structure of Mpro from SARS-CoV-2 and discovery of its inhibitors. Nature 582(7811):289-293. https://doi.org/10.1038/s41586-020-2223-y

7. Macchiagodena M, Pagliai M, Procacci P (2020) Identification of potential binders of the main protease 3CLpro of the COVID-19 via structure-based ligand design and molecular modeling. Chem Phys Lett 750:137489. https://doi.org/10.1016/j.cplett.2020. 137489

8. Zhang L, Lin D, Sun X, Curth U, Drosten C, Sauerhering L, Becker S, Rox K, Hilgenfeld R (2020) Crystal structure of SARS$\mathrm{CoV}-2$ main protease provides a basis for design of improved $\alpha$-ketoamide inhibitors. Science (New York, NY) 368(6489):409_ 412. https://doi.org/10.1126/science.abb3405

9. Koskiniemi H, Metsä-Ketelä M, Dobritzsch D, Kallio P, Korhonen H, Mäntsälä P, Schneider G, Niemi J (2007) Crystal structures of two aromatic hydroxylases involved in the early tailoring steps of angucycline biosynthesis. J Mol Biol 372(3):633-648. https://doi. org/10.1016/j.jmb.2007.06.087

10. Krohn K, Rohr J (1997) Angucyclines: total syntheses, new structures, and biosynthetic studies of an emerging new class of antibiotics. In: Bioorganic chemistry deoxysugars, polyketides and related classes: synthesis, biosynthesis, enzymes. Springer, pp 127-195

11. Rohr J, Thiericke R (1992) Angucycline group antibiotics. Nat Prod Rep 9(2):103-137. https://doi.org/10.1039/NP9920900103

12. Korynevska A, Heffeter P, Matselyukh B, Elbling L, Micksche M, Stoika R, Berger W (2007) Mechanisms underlying the anticancer activities of the angucycline landomycin E. Biochem Pharmacol 74(12):1713-1726. https://doi.org/10.1016/j.bcp.2007.08.026

13. Grabley S, Hammann P, Hütter K, Kluge H, Thiericke R, Wink J, Zeeck A (1991) Secondary metabolites by chemical screening. Part 19. SM 196 A and B, novel biologically active angucyclinones from Streptomyces sp. J Antibiot 44(6):670-673

14. Tsunakawa M, Komiyama N, Tenmyo O, Tomita K, Kawano K, Kotake C, Konishi M, Oki T (1992) New antiviral antibiotics, cycloviracins B1 and B2. I. Production, isolation, physicochemical properties and biological activity. J Antibiot (Tokyo) 45(9):1467-1471. https://doi.org/10.7164/antibiotics.45.1467

15. Tsunakawa M, Kotake C, Yamasaki T, Moriyama T, Konishi M, Oki T (1992) New antiviral antibiotics, cycloviracins B1 and B2. II Structure determination J Antibiot (Tokyo) 45(9):1472-1480. https://doi.org/10.7164/antibiotics.45.1472

16. Al-Bustany HA (2015) Screening of angucycline antibiotics as potential drug candidates against MRSA by docking analysis. Dicle University, Diyarbakır

17. BIOVIA DS (2019) Discovery Visualizer Studio, v19.1.0.18287, edn. Dassault Systèmes, San Diego

18. Morris GM, Huey R, Lindstrom W, Sanner MF, Belew RK, Goodsell DS, Olson AJ (2009) AutoDock4 and AutoDockTools4: automated docking with selective receptor flexibility. J Comput Chem 30(16):2785-2791. https://doi.org/10.1002/jcc.21256

19. Case DA, Belfon K, Ben-Shalom IY, Brozell SR, Cerutti DS, Cheatham TE, Cruzeiro VWD, Darden TA, Duke RE, Giambasu G (2020) AMBER 20. University of California, San Francisco

20. Daina A, Michielin O, Zoete V (2017) SwissADME: a free web tool to evaluate pharmacokinetics, drug-likeness and medicinal chemistry friendliness of small molecules. Sci Rep 7:42717. https://doi.org/10.1038/srep42717

21. Jakalian A, Bush BL, Jack DB, Bayly CI (2000) Fast, efficient generation of high-quality atomic charges. AM1-BCC model: I. Method. J Comput Chem 21(2):132-146. https://doi.org/10.1002/ (SICI)1096-987X(20000130)21:2<132::AID-JCC5>3.0.CO;2-P

22. Jorgensen WL, Chandrasekhar J, Madura JD, Impey RW, Klein ML (1983) Comparison of simple potential functions for simulating liquid water. J Chem Phys 79(2):926-935. https://doi.org/10. 1063/1.445869

23. Wang J, Wolf RM, Caldwell JW, Kollman PA, Case DA (2004) Development and testing of a general amber force field. J Comput Chem 25(9):1157-1174. https://doi.org/10.1002/jcc.20035

24. Pettersen EF, Goddard TD, Huang CC, Couch GS, Greenblatt DM, Meng EC, Ferrin TE (2004) UCSF Chimera-a visualization system for exploratory research and analysis. J Comput Chem 25(13):1605-1612. https://doi.org/10.1002/jcc.20084

25. Cornell WD, Cieplak P, Bayly CI, Gould IR, Merz KM, Ferguson DM, Spellmeyer DC, Fox T, Caldwell JW, Kollman PA (1995) A second generation force field for the simulation of proteins, nucleic acids, and organic molecules. J Am Chem Soc 117(19):5179-5197. https://doi.org/10.1021/ja00124a002

26. Darden T, York D, Pedersen L (1993) Particle mesh Ewald: an $\mathrm{N} \cdot \log (\mathrm{N})$ method for Ewald sums in large systems. J Chem Phys 98(12):10089-10092. https://doi.org/10.1063/1.464397

27. Kollman PA, Massova I, Reyes C, Kuhn B, Huo S, Chong L, Lee M, Lee T, Duan Y, Wang W, Donini O, Cieplak P, Srinivasan J, Case DA, Cheatham TE (2000) Calculating structures and free energies of complex molecules: combining molecular mechanics and continuum models. Acc Chem Res 33(12):889-897. https://doi.org/10.1021/ar000033j

28. Srinivasan J, Cheatham TE, Cieplak P, Kollman PA, Case DA (1998) Continuum solvent studies of the stability of DNA, RNA, and PHOSPHORAMIDATE-DNA helices. J Am Chem Soc 120(37):9401-9409. https://doi.org/10.1021/ja981844+

29. Ercan S, Arslan N, Kocakaya SO, Pirinccioglu N, Williams A (2014) Experimental and theoretical study of the mechanism of hydrolysis of substituted phenyl hexanoates catalysed by globin in the presence of surfactant. J Mol Model 20(3):2096. https:// doi.org/10.1007/s00894-014-2096-9

30. Ercan S, Pirinccioglu N (2013) Computational design of a fulllength model of HIV-1 integrase: modeling of new inhibitors and comparison of their calculated binding energies with those previously studied. J Mol Model 19(10):4349-4368. https://doi.org/10. 1007/s00894-013-1943-4

31. Jin Z, Zhao Y, Sun Y, Zhang B, Wang H, Wu Y, Zhu Y, Zhu C, Hu T, Du X, Duan Y, Yu J, Yang X, Yang X, Yang K, Liu X, Guddat LW, Xiao G, Zhang L, Yang H, Rao Z (2020) Structural basis for the inhibition of SARS-CoV-2 main protease by antineoplastic drug carmofur. Nat Struct Mol Biol 27(6):529-532. https://doi. org/10.1038/s41594-020-0440-6

32. Al-Shar'i NA (2020) Tackling COVID-19: identification of potential main protease inhibitors via structural analysis, virtual screening, molecular docking and MM-PBSA calculations. J Biomol Struct Dyn. https://doi.org/10.1080/07391102.2020.1800514

33. Mittal L, Kumari A, Srivastava M, Singh M, Asthana S (2020) Identification of potential molecules against COVID-19 main protease through structure-guided virtual screening approach. J Biomol Struct Dyn. https://doi.org/10.1080/07391102.2020.17681 51

34. Wang J (2020) Fast identification of possible drug treatment of coronavirus disease-19 (COVID-19) through computational drug repurposing study. J Chem Inf Model 60(6):3277-3286. https:// doi.org/10.1021/acs.jcim.0c00179

35. Kanhed AM, Patel DV, Teli DM, Patel NR, Chhabria MT, Yadav MR (2021) Identification of potential Mpro inhibitors for the 
treatment of COVID-19 by using systematic virtual screening approach. Mol Divers 25(1):383-401. https://doi.org/10.1007/ s11030-020-10130-1

36. Allen WJ, Balius TE, Mukherjee S, Brozell SR, Moustakas DT, Lang PT, Case DA, Kuntz ID, Rizzo RC (2015) DOCK 6: impact of new features and current docking performance. J Comput Chem 36(15):1132-1156. https://doi.org/10.1002/jcc.23905

Publisher's Note Springer Nature remains neutral with regard to jurisdictional claims in published maps and institutional affiliations.

\section{Authors and Affiliations}

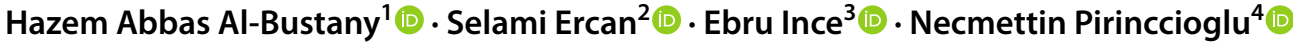

1 Department of Basic Science, College of Medicine, Hawler Medical University, Erbil, Iraq

2 Department of Nursing, School of Health, Batman University, Batman, Turkey
3 Department of Biology, Dicle University, 21280 Diyarbakir, Turkey

4 Department of Chemistry, Dicle University, 21280 Diyarbakir, Turkey 